\title{
Historein
}

Vol 1 (1999)

\section{History and Semiotics}

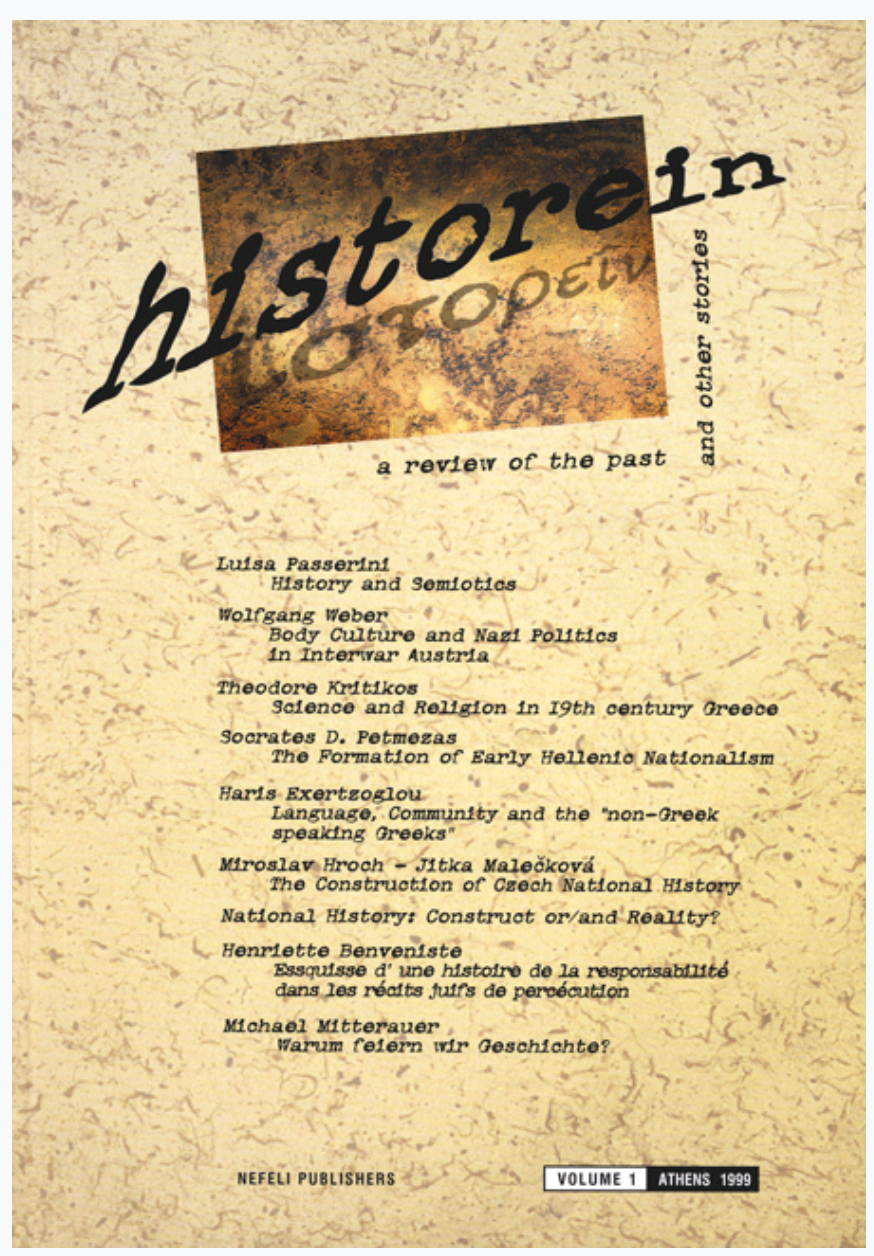

\section{Millennien und andere Jubeljahre: Warum feiern wir Geschichte?}

Michael Mitterauer

doi: $10.12681 /$ historein.131

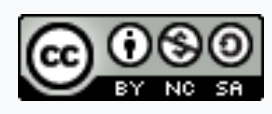

This work is licensed under a Creative Commons Attribution-NonCommercialShareAlike 4.0.

\section{To cite this article:}

Mitterauer, M. (2000). Millennien und andere Jubeljahre: Warum feiern wir Geschichte?. Historein, 1, 125-146. https://doi.org/10.12681/historein.131 


\section{Millennien}

\section{und andere}

\section{Jubeljahre:}

\section{Warum}

feiern wir

\section{Geschichte?}

Das Jubeljahr 1996 ist abgelaufen. Schon von den Vorbereitungen an war es von einer gewissen Skepsis begleitet: Ließ es sich historisch vertreten, daß der Staat Österreich in diesem Jahr ein Millennium begeht? 1946 hatte man 950 Jahre Österreich gefeiert. Allzu deutlich aber war der politische Hintergrund dieses Jubiläums. Die wiedererstandene Republik suchte nach einem historischen Anlaß, inre Identität durch eine Gedenkfeier zu stärken. Die erste Nennung des Namens "Österreich" in einer Königsurkunde von 996 gab dafür einen Ansatzpunkt. Als man sich ein halbes Jahrhundert später dafür entschied, neuerlich ein Gedenkjahr vorzubereiten, wußte man sehr wohl um die Problematik des Anlaßfalls. Österreich ist älter als sein Name. Und die überlieferte Erstnennung dieses Namens ist zufällig. Man blieb trotzdem bei diesem Datum. Historische Schwierigkeiten suchte man terminologisch zu umgehen: Man sprach statt von "Österreichs Geburtstag" von "Österreichs Namenstag" - in völliger Verkennung dessen, was das Wesen des Namenstages ausmacht. Man bezeichnete die OstarrichiUrkunde als "Österreichs Taufschein"auch hier in einer verfehlten Parallele zu lebensgeschichtlichen Bedeutsamkeiten. Hat die Diskussion um den Anlaßfall dazu geführt, daß im Jubeljahr so wenig Jubelstimmung aufkam? Die skeptische Grundstimmung ist wohl mehr aus der Gegenwart als aus der Geschichte zu erklären. Vielleicht hatte diese Skepsis aber auch inr Gutes: Wo Geschichte ohne Überschwang gefeiert wird, kann es auch nicht so leicht zum Mißbrauch historischen Gedenkens kommen.

Das Jubeljahr 2000 steht unmittelbar bevor. Sogenannte "Jahrtausenduhren" sind bereits installiert - in Linz etwa -, die die letzten 
tausend Tage bis zur Jahrtausendwende sichtbar machen sollen. In aller Welt werden schon Vorbereitungen für das Millenniumsspektakel getroffen. Im "Standard" ist darüber zu lesen: "Zu den weltweit attraktivsten Veranstaltungen in der Nacht der Nächte gehört der Kaiserball in der Wiener Hofburg. Die Kartenpreise liegen derzeit zwischen 2200 und 5600 Schilling (mit Diner) ... Ob die Rolling Stones wirklich zu Silvester 1999 im Londoner Wembleystadion 100.000 frostfeste Fans beglücken werden, ist noch nicht entschieden. Fix sind hingegen World Millennium Charity Balls in 23 Ländern der Erde, die alle via Satellitenschaltung verbunden werden sollen. Von der chinesischen Mauer, über die Akropolis und den Eiffelturm bis hin zu den ägyptischen Pyramiden - überall wird es heißen: Alles Walzer. Dazu soll auf dem alten Flughafen Tempelhof in Berlin das größte Feuerwerk aller Zeiten in die Luft gepulvert werden." Aber was wird hier eigentlich so aufwendig gefeiert? Die Geburt Jesu vor 2000 Jahren? Daran wird sicher der Papst erinnern, wenn er zu Weihnachten 1999 die "Porta Santa" im Petersdom öffnet und damit das "Heilige Jahr" einleitet. Die Vorbereitungen für dieses in Superlativ-Dimensionen geplante "Anno santo" sind ja auch schon angelaufen. Mit dem geschichtlichen Anlaßfall wird allerdings auch der Papst seine Schwierigkeiten haben. Wir wissen es inzwischen: Dionysius Exiguus, der im 6. Jahrhundert das Geburtsjahr Christi zu berechnen versuchte, hat sich geirrt. Der 2000. Jahrestag ist längst vorbei. Auch in Rom wurde er nicht begangen. Den Millenniumsfeiern zu Beginn des Jahres 2000 werden Fragen der historischen Exaktheit nichts anhaben - ebensowenig die rechnerische Überlegung, daß das dritte Jahrtausend erst am 1. Jänner 2001 beginnt.

Jubeljahre rundherum. Als Österreich sein Millennium beging, wurde etwa in Frankreich das 1500-Jahre-Jubiläum der Taufe des Frankenkönigs Chlodwig gefeiert. Der Front-National-Chef. Jean-Marie Le Pen tat sich dabei besonders hervor. Er sprach in diesem Zusammenhang vom "Gründerakt der ältesten Nation Europas und einer der größten Zivilisationen der Welt". Staatlicherseits blieb man eher zurückhaltend. Vergeblich rief der Pariser Erzbischof Präsident Chirac auf: "Wenn ich Präsident dieser Republik wäre, würde ich das Chlodwig-Kidnapping durch Le Pen nicht zulassen." Daß Papst Johannes Paul II. das Gedenken an dieses historische Ereignis aufgriff, führte eher zu weiterer Polarisierung. Schon im Vorfeld des Gedenkjahres hatte er gefragt: "Frankreich, älteste Tochter der Kirche, was hast du mit dem Versprechen deiner Taufe gemacht?" - eine sicher nicht unproblematische Personifizierung einer Nation, verbunden mit einer noch problematischeren Erwartung für die Gegenwart. Es braucht nicht zu verwundern, daß von Gegnern des Jubiläums gefragt wurde, warum die Kirche einen "Krieger, Unzüchtler, Folterer und Mörder" ehre, der sich auch durch die Taufe nicht geändert habe. Die Wogen gingen hoch. Für den Papstbesuch mit seiner Abschlußveranstaltung am Ort der Chlodwig-Taufe in Reims wurde Schlimmes befürchtet. Es kam anders. Der Papst wählte in seinen Ansprachen äußerst vorsichtige Formulierungen. Die Gegenseite steckte zurück. Es blieb bei einem Sturm im Wasserglas. Daß es sich um ein Jubiläum zum falschen Zeitpunkt handelte, weil Chlodwigs Taufe höchstwahrscheinlich gar nicht 496 stattgefunden hat, blieb für den Ablauf des aktuellen Ereignisses völlig ohne Bedeutung. 


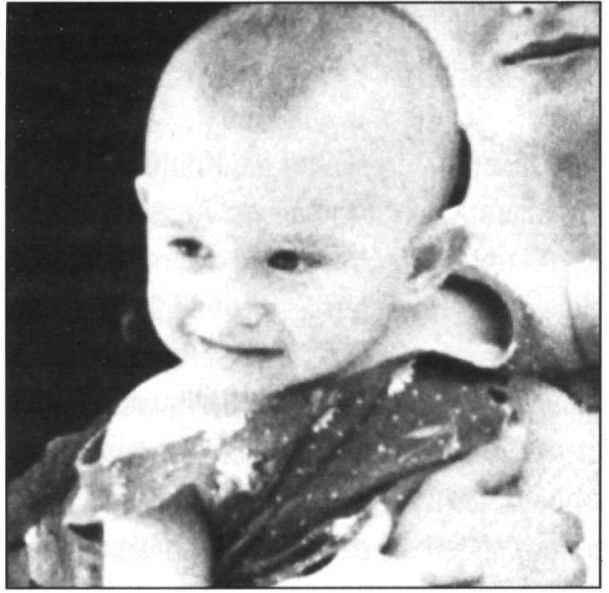

Die mögliche politische Brisanz von Jubiläen läßt sich insgesamt am Beispiel von Papstbesuchen in Gedenkjahren schön veranschaulichen. 1983 kam Johannes Paul II. zum Katholikentag nach Wien. Die Terminwahl dieses Katholikentags wurde - wie schon fünfzig Jahre zuvor - durch das Jubiläum der Befreiung Wiens von den Türken im September 1683 bestimmt. Die historischen Bezüge dieses Papstbesuchs lösten im Vorfeld heftige Diskussionen aus. Sie fanden nicht nur in der österreichischen sondern auch in der internationalen Presse ihren Niederschlag. So schrieb etwa damals "Die Zeit" (7.1.83): "Dieses

Zusammentreffen von Türkentriumph, Katholikenfeier und polnischem Papst ist sicherlich keineswegs zufällig, sondern von den Veranstaltern genauso programmiert. Die Terminwahl läßt eine ganz bestimmte historische Identifikation erkennen. Erinnert werden soll wohl an das damalige Bündnis von Papst, Kaiser und Polenkönig, das 1683 vor Wien im "Sieg der bedrohten Christenheit" über den "Feind aus dem Osten" gipfelte. In einer frühen Planungsphase des Besuches war diese historische Parallele ganz eklatant: Der ursprünglichen Idee nach sollte Papst Johannes Paul für seine polnischen Landsleute am Tag der Türkenschlacht eine Messe auf dem Kahlenberg lesen - genau dort, wo vor 300 Jahren der Polenkönig Sobieski am Morgen der Schlacht die Messe feierte. Nur wegen der Organisations- und Platzprobleme wurde dieser Gedanke fallengelassen. Auch ohne Kahlenberg sind die historischen Assoziationen deutlich genug - ebenso wie die politischen Dimensionen des Wiener Spektakels ... Im geheimen wächst freilich das Unbehagen. Kulturpolitiker, kritische Katholiken und Historiker beginnen die vehementen Zurüstungen zur Selbstfeier Wiens als Glaubensbollwerk gegen den "Feind aus dem Osten" in Frage zu stellen. Sie fragen, was - und vor allem: gegen wen - hier eigentlich mobilisiert wird. Nicht wenige Katholiken fühlen sich angesichts der Geister, die hier gerufen werden, von Zauberlehrlings-Ängsten ergriffen. Immerhin hält die österreichische Katholikentags-Geschichte auch ein paar mulmige Assoziationen bereit. So war der Katholikentag 1933 ein Höhepunkt des politischen Katholizismus in Österreich und ist vom Odium des Austrofaschismus belastet ... Daß ausgerechnet auf dem historisch so belasteten Heldenplatz die päpstliche Massenkundgebung "Europa - Erbe und Auftrag der Christen" stattfinden soll, veranlaßt die Katholikentags-Organisatoren inzwischen zu allerhand Abgrenzungsbeteuerungen. Zwar haben sie mit inrer Terminwahl des September 1983 die fatalen historischen Anklänge selber heraufbeschworen; unter dem Druck interner Kritik aber wollen sie die heiklen Assoziationen nach Kräften verscheuchen ... Während der Kulturstadtrat und der Kardinal zu Beginn des monströsen Wiener Jubeljahres vor allem mit dem Gräbenzuschütten beschäftigt sind, fragen sich ein paar kritische Historiker an der Wiener Universität immer lauter, im Namen welchen Datum-Fetischismus die Gräben überhaupt aufgerissen werden." 
Ganz anders als "Die Zeit" sah der "Osservatore Romano" die Debatten um die historischen Bezüge des Papstbesuchs in Wien. In seiner deutschsprachigen Sonderausgabe zu diesem Anlaß heißt es: "Heute sieht sich das österreichische Volk der Gefahr gegenüber, im Zwielicht moralischer Permissivität, westlicher Agnostik und nihilistischer Zersetzung die Konturen seiner religiösen und nationalen Identität aus den Augen zu verlieren ... Haßmotivierte Angstneurosen auch unter Christen, die ihren gesellschaftspolitischen Standort wechseln, artikulieren sich als Konteste gegen die Vereinigten Staaten, den letztverbliebenen Garanten jener abendländischen Freiheit, für die drei Jahrhunderte zuvor" gekämpft worden sei. "Ein Scherbenhaufen weltpolitischer Orientierungslosigkeit ist das Resultat der konsequenten Umfunktionierung österreichischen Geschichtsbewußtseins. Wer meint der Heilige Vater proklamiere durch das Septemberdatum 1983 einen neuen Sturm vom

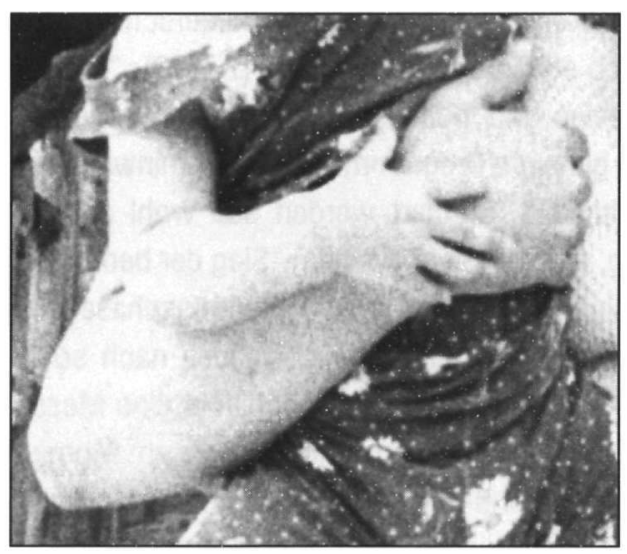
Kahlenberg gegen die geistigen und militärischen Truppen aus dem Osten, hat die Visite des Vaters aller Christen in seiner polnischen Heimat in den Junitagen 1983 nicht begriffen. Wer hingegen sozusagen Wien als "offene Kirche" für die geschichtlich widerlegte Pseudo-Heilslehre des marxistischen Sozialismus etabliert und basisdemokratische Innovationen im Gottesvolk als Antithese zur hierarchischen Struktur des Corpus Christi Mysticum fordert, verdient die gleiche Abfuhr wie Ernesto Cardenal in Managua."

Argumentationen und Wortwahl in dieser Auseinandersetzung um die Gestaltung des Papstbesuchs in Wien im Jubeljahr 1983 zeigen deutlich, wie stark Identität in der Gegenwart durch historische Gedenkfeiern betroffen sein kann. Trotz der Heftigkeit der Debatte führte sie in einigen wesentlichen Punkten zu Klärungen. Die unter dem Titel "Europa - Erbe und Auftrag der Christen" geplante Veranstaltung auf dem Heldenplatz wurde umprogrammiert. Und es darf wohl auch als Folgewirkung dieser Diskussionen angesehen werden, daß die Reden aus Anlaß des Papstbesuchs im wesentlichen von problematischen Bezügen auf die Geschichte frei blieben. Ihren Ausgang genommen hatten sie von einer Lehrerfortbildungszeitschrift. Die "Beiträge zur historischen Sozialkunde" veröffentlichten Ende 1982 eine Themennummer "Türkenjubiläum 1983. Heroenkult oder Strukturanalyse?" und darin einen Beitrag "Politischer Katholizismus, Österreichbewußtsein und Türkenfeindbild. Zur Aktualisierung von Geschichte bei Jubiläen”. Von der Breitenwirkung ihrer Kritik waren die Autoren selbst überrascht. Das Schicksal Ernesto Cardenals, vom Papst nicht zum Ringkuß zugelassen zu werden, blieb ihnen erspart. Sie waren gar nicht eingeladen.

Noch viel brisanter als der Besuch in Wien im Türkenjahr war sicher die Papstreise nach Santo Domingo zum Columbus-Jubiläum 1992. Wie hier im Gedenkjahr ein Katholikentag veranstaltet wurde, so dort eine Bischofskonferenz - und zwar eine für ganz Lateinamerika, die der Papst zum historischen Datum der "Entdeckung Amerikas", dem 12. Oktober, eröffnete. Termin- und 
Ortswahl zwangen zur Auseinandersetzung mit der Geschichte. Schon in einer Vorausschau auf das Jubiläum schloß sich Johannes Paul II. ausdrücklich einer Erklärung Leos XIII. zum 400. Jahrestag an, der in der Landung Christoph Columbus' "ein Zeichen der göttlichen Vorsehung" erblickte und dieses Ereignis als "die größte und wunderbarste unter den menschlichen Taten" bezeichnete. Die Bischofskonferenz stellte er unter das Motto "500 Jahre Evangelisierung Lateinamerikas" und rief zur "Neuevangelisierung" des Kontinents auf. Die kirchenoffizielle Deutung des Gedenkanlasses fand massiven Widerspruch. Schon 1986 formulierten die Vertreter von dreißig Indiovölkern aus fünfzehn lateinamerikanischen Staaten in einem "Eingeborenen-Manifest" ihre "totale Ablehnung dieser triumphalistischen Feiern". Als Gründe nannten sie u. a.: "Es hat keine Entdeckung oder authentische Evangelisierung gegeben, wie behauptet wird, sondern es war statt dessen eine Invasion mit folgenden Konsequenzen: a) ein Völkermord durch den Okkupationskrieg, Infektionen mit europäischen Krankheiten, Tod durch Überausbeutung und Trennung von Eltern und Kindern, der zur Ausrottung von über 75 Millionen unserer Brüder geführt hat; b) gewaltsame Wegnahme unseres Landes; c) Desintegration unserer sozialen, politischen und kulturellen Organisationsformen; d) ideologische und religiöse Unterwerfung auf Kosten der inneren Natur unseres eigenen religiösen Glaubens." Von der Vielzahl kritischer Stimmen im Vorfeld des Papstbesuchs zum Columbus-Jubiläum sei stellvertretend Bischof Erwin Kräutler genannt, der einem Beitrag aus der Sicht der Befreiungstheologie schlicht den Titel 'Feierstunde zum Völkermord?" gab. Nach den scharfen Debatten, die dem Jubiläum vorangegangen waren, fielen die Aussagen des Papstes über die aktuelle Bedeutsamkeit des historischen Anlasses äußerst vorsichtig aus. Auf der lateinamerikanischen Bischofskonferenz in Santo Domingo allerdings wurde ein Antrag von 33 Bischöfen abgelehnt, der einen öffentlichen Reueakt verlangte, in dem die Kirche ihre Mitschuld an dem bei der Eroberung an den Indios begangenen Unrecht bekennt. Der Konferenzvorsitzende begründete die Ablehnung damit, daß ein solcher Reueakt leicht von falscher Seite, wie von bestimmten Indianergruppen oder Sekten, mißbraucht werden könnte.

Die heftigen Debatten vor und um die Jubiläumsfeierlichkeiten von 1992 haben nicht nur in der Beurteilung des Anlasses neue Sichtweisen gebracht, sondern auch über die Funktion von Jubeljahren nachdenken lassen. Zwei Missionsdiözesen in Panama traten diesbezüglich mit einem bemerkenswerten Vorschlag an die Weltöffentlichkeit: Die 500-Jahrfeier sollte als ein Jubeljahr im Sinn der Bibel begangen werden, als ein Gnadenjahr, in dem alle Schulden bedingungslos vergeben werden. "Dieses biblische Gesetz, von Moses verkündet und von Jesus aktualisiert, muß für Lateinamerika heute eine historische Realität sein.” Ausführlich wird diese Forderung auf Schuldennachlaß für die lateinamerikanischen Staaten im Jubeljahr mit Stellen aus den Büchern Exodus, Deuteronomium und Levitikus sowie aus dem LukasEvangelium argumentiert. Sicher - das Jobel-Jahr der Bibel ist, bei allen etymologischen Zusammenhängen, etwas grundsätzlich anderes als ein historisches Jubiläum heute; aber als Anwendung biblischer Grundsätze auf die Gegenwart war die Forderung legitim, zumal je gerade der Beginn einer Neuevangelisierung gefordert wurde. Beim Papstbesuch in Santo Domingo wurde auf den Vorschlag nicht Bezug genommen.

Für das "Ostarrichi"-Jubiläum von 1996 war ein zweiter Papstbesuch in Österreich im 
Gespräch. Es wurde schon über Selig- bzw. Heiligsprechungen spekuliert, die aus diesem Anlaß erfolgen sollten - auch das eine eminent geschichtsbezogene Facette solcher Visiten in historischen Gedenkjahren. Im "Columbus-Jahr" 1992 gab es etwa diesbezüglich Gerüchte um Isabella die Katholische, deren Rolle bei der ebenfalls 1492 erfolgten Judenvertreibung aus Spanien aber damit in die Diskussion gekommen wäre. Es wäre spannend gewesen, was Johannes Paul II. bei einem Besuch aus Anlaß des Millenniums zu "Österreichs Taufschein" und "Österreichs Namenstag" gesagt hätte, noch spannender, wie es inm gelungen wäre, den historischen Anlaß mit der kirchenpolitischen Situation in Österreich zu verbinden. Mit politischer Brisanz hätte man jedenfalls in diesem Jubeljahr rechnen dürfen. Es kam anders. Der Plan eines zweiten Österreich-Besuchs wurde fallengelassen. Aber auch die Absage verweist auf die politische Bedeutsamkeit von Jubeljahren.

Eines wird wohl aus den wenigen hier behandelten Beispielen klar: Jubiläen und Gedenktage haben nicht nur mit der Vergangenheit zu tun, sondern ebenso auch mit der jeweiligen Gegenwart. In dieser Allgemeinheit gilt die Feststellung für jede Beschäftigung mit Geschichte. Bei Jubiläen handelt es sich allerdings um einen ganz spezifischen Umgang mit Geschichte aus Interessen der Gegenwart. Jubiläen werden gefeiert. Und das Feiern von Geschichte ist mit anderen Formen der Beschäftigung mit Vergangenheit schwierig zu vereinen. Konrad Ließmann hat kürzlich dieses Problem von Jubiläen und Gedenktagen auf die prägnante Formel gebracht: "Entweder man denkt oder man feiert. Überall dort, wo gefeiert und gleichzeitig gedacht - oder gar bedacht - werden soll, spießt es sich." Darum geht es mir auch: Um die Widersprüche von Geschichte-Denken und Geschichte-Feiern. Ich habe gar nichts gegen das Feiern. Aber brauchen wir dazu die Geschichte? Und wenn schon Geschichte-Feiern, dann gilt es dabei, verantwortungsbewußt zu bedenken, welche Auswirkungen "Jubelgeschichte" jeweils für politisches und gesellschaftliches Bewußtsein hat. Ein hohes Maß an Verantwortung liegt diesbezüglich bei den Historikern. Innen kommt wohl primär die Aufgabe des GeschichteDenkens zu. Sie werden aber durchaus auch für's Geschichte-Feiern in Dienst genommen oder lassen sich dafür in Dienst nehmen. In Hinblick auf die gemeinsamen Wurzeln dieser beiden Formen des Umgangs mit Vergangenheit ist es gar nicht so verwunderlich, daß immer wieder der Versuch gemacht wird, Unverbindbares zu verbinden.

In der Einladung zu dieser Wiener Vorlesung wurde mit zwei Zitaten auf die Veranstaltung eingestimmt. Das eine von innen macht gerade auf diese Spannung von Geschichte-Denken und Geschichte-Feiern aufmerksam. In einem Interview mit "Geschichte und Gesellschaft" formulierte Pierre Bourdieu: "Die zentrale Position der Geschichte im universitären Feld ... schwankt zwischen dem Modernismus einer Wissenschaft der historischen Tatsachen und dem vorsichtigen Akademismus bzw. Konformismus einer älteren literarischen Tradition ... Oder genauer gesagt: Zwischen einer Forschung, die notwendigerweise kritisch ist, weil sie sich auf Gegenstände bezieht, die gegen die landläufigen Vorstellungen konstruiert worden sind und die von der offiziösen Geschichte der Gedenktage vollkommen ignoriert werden, und auf der anderen Seite einer offiziellen oder halb-offiziellen Geschichte, die sich der Verwaltung des kollektiven Gedächtnisses widmet, indem sie an den vielfältigen Gedenkfeiern teilnimmt und die sakrosankten Archive konserviert, jenes Staatsgedächnisses, das der Staat eben durch die 
Geschichtswissenschaft kontrolliert." In der Geschichte und der Theorie der Geschichtswissenschaft werden diese beiden ganz unterschiedlichen Entwicklungsstränge in der Regel nicht unterschieden. Umso hilfreicher ist der Hinweis des Wissenschaftssoziologen Bourdieu: die Gedenktagsgeschichte unterscheidet sich in Zielen und Zugangsweisen sehr wesentlich von einer kritischen Geschichtswissenschaft. Es wäre für das Selbstverständnis des Faches sehr wichtig, dem Spannungsverhältnis zwischen diesen beiden Formen des Umgangs mit Vergangenheit nachzugehen. Ein Beitrag dazu wird hier versucht. Die Frage: Warum feiern wir Geschichte? führt über die Geschichte von Jubiläen und Gedenktagen zu bestimmten Folgewirkungen, die für das Feiern von Geschichte typisch sind.

Das zweite Zitat, das vom Einladungstext her auf diese "Wiener Vorlesung" vorbereiten soll, eröffnet einen ganz anderen Zugang zum Thema: "Das Jahrhundert, das Jahrtausend nähert sich seinem Ende. Es wird Zeit, nüchtern Bilanz zu ziehen. Wer, wenn nicht der Historiker, sollte dies sachgerecht leisten? Es sind die alten Fragen, die zu stellen sind: Wer sind wir? Woher kommen wir? Wohin gehen wir? - aber es können nicht die alten Antworten sein. Ausgangspunkt jeder lebendigen Historie muß die Gegenwart sein. Ihre brennenden Fragen sind das Triebwerk, das historische Reflexion in Gang setzt und hält." Der Autor, der der jüngeren Generation der österreichischen Geschichtswissenschaft angehört, ist sicher nicht zu den GedenktagsHistorikern im Sinne Pierre Bourdieus zu rechnen. Sein Konzept einer an Gegenwartsproblemen orientierten, lebendigen Historie steht gewiß in einem ganz anderen Kontext. Aber warum sollte gerade vor der Jahrhundert- bzw. Jahrtausendwende ein besonderer Anlaß sein, Bilanz zu ziehen. Diese an bestimmte Zeiten gebunden gedachte Notwendigkeit des Bilanzierens kommt dem "Zwang der runden Zahl" sehr nahe, auf die sich Jubiläumshistoriker immer wieder berufen. Wer zwingt da eigentlich wen? Welcher Zwang besteht nach 50, 100, 950 oder 1000 Jahren zu feiern oder über Vergangenes Bilanz zu ziehen.

Bei einer sehr emotional geführten Diskussion im Vorfeld des Türkenjubiläums von 1983 hat der damalige Kulturstadtrat von Wien mit lebensgeschichtlichen Parallelen argumentiert. So wie es selbstverständlich sei, alten Menschen zum 80. oder 90. Geburtstag und zur Goldenen Hochzeit zu gratulieren, so selbstverständlich müsse auch 300 Jahre nach der erfolgreich abgewehrten Türkenbelagerung gefeiert werden. Der Verweis auf die soziale Pflicht zur Ehrung alter Menschen, ist sicher eine geschickte Immunisierungsstrategie. Aber stimmt die Parallele zwischen Lebensgeschichte und Staatsgeschichte, die hier gezogen wird? Sind persönliche Jubiläen nicht etwas ganz anderes als Jubiläen von Staaten, Kirchen und anderen Großgruppen, bei denen es in der Regel gerade nicht um selbst Erlebtes und selbst Erfahrenes geht? Von einem "Zwang der runden Zahl" kann schon im persönlich-familiären Bereich gewiß nicht gesprochen werden. Das Feiern "runder" Geburts- oder Hochzeitstage ist eine - historisch relativ junge - gesellschaftliche Konvention. Und so läßt sich hier auch nichts auf die staatliche oder kirchliche Ebene übertragen. Geschichte bei Jubiläen feiern ist nicht "Zwang der runden Zahl". Es ist Zwang der Tradition - und diese sollte man überdenken.

Vom "Zwang der runden Zahl” im Zusammenhang mit Jubiläen zu sprechen, bedeutet eine Enthistorisierung des Phänomens. Es wird dabei von unhinterfragten Prämissen ausgegangen: 
Daß bestimmte historische Ereignisse gedacht werden müssen, daß dieses Gedenken in bestimmten zeitlichen Abständen erfolgen muß, daß dieses Gedenken in der Form einer Feier erfolgen muß. Solchen Prämissen wird eine gleichsam überzeitlich gleichbleibende Geltung zugesprochen - das Phänomen Jubiläum gleichsam als eine anthropologische Konstante. Das ist sicher unhistorisch gedacht. Ein Blick auf die Geschichte der Jubiläen zeigt es eindeutig: Diese Form des Umgangs mit Geschichte ist eine sehr spezifische. Sie begegnet zeitlich und regional begrenzt sowie in sich wiederum vielfältig differenziert. So nimmt ein Blick zurück sehr rasch dem Phänomen Jubiläum jene unhinterfragte Selbstverständlichkeit, die es aus der Praxis der Gegenwart zu haben scheint. Umso erstaunlicher ist es, daß gerade Historiker für diese unhistorische Betrachtungsweise besonders anfällig erscheinen. Bourdieus Unterscheidung zweier Grundtypen geschichtswissenschaftlichen Zugangs hilft hier weiter. Wir müssen die "Gedenktage-Geschichte" zum Gegenstand der "kritischen Geschichtswissenschaft" machen. Das führt zu einer Antwort auf unsere Ausgangsfrage: Warum feiern wir Geschichte?

Geht man den historischen Wurzeln des Geschichte-Feierns nach, so führen die Entwicklungslinien stets in religiöse Zusammenhänge zurück. Der interkulturelle Vergleich zwischen Religionsgemeinschaften der Vergangenheit bzw. der Gegenwart zeigt jedoch, daß es sich beim Feiern von Geschichte zu bestimmten "heiligen Zeiten" keineswegs um ein allgemein verbreitetes religiöses Grundphänomen handelt. Es hängt mit der spezifischen Bedeutung des Sich-Erinnerns in einer Religion zusammen, ob und in welcher Form sie eine historisch orientierte Festkultur ausbildet. Im Christentum kommt der Erinnerung an Heilsgeschehen der Vergangenheit zentraler Stellenwert zu. Sehr treffend wurde diese Eigenart als "Memorialcharakter des Christentums" bezeichnet.

Die Besonderheit des Konzepts der Heilgeschichte und damit eine besondere Kultur religiösen Erinnerns ist Christentum und Judentum gemeinsam. Es handelt sich beim Ursprung dieser Gemeinsamkeit um eine sehr spezifische Form der Theologisierung von Geschichte. Die Vorstellung, daß Gott bzw. Götter verursachend in den Ablauf der Geschichte sowie in die einzelnen menschlichen Lebensschicksale eingreifen, bestimmt das Geschichtsbild nicht nur der Israeliten sondern auch anderer vorderorientalischer Kulturen der Frühzeit. Die einmalige Besonderheit der israelitischen Konzeption von Heilgeschichte ist der Gedanke des Bündnisses zwischen Gott und seinem Volk. Alles was dem Volk widerfährt, steht in Zusammenhang mit seiner Treue bzw. Untreue gegenüber dem göttlichen Partner. Nicht das einseitige Eingreifen der Gottheit ist in dieser Form der Theologisierung von Geschichte entscheidend, sondern die wechselseitige Selbstverpflichtung der Bündnispartner, die sich durch ihr Handeln gegenseitig beeinflussen. Heilgeschichte als Geschichte des Bündnisses Gottes mit seinem auserwählten Volk in diesem Verständnis war neu. Sie stellt den Kontext dar, in dem die religiös-historische Gedenktagskultur des Judentums in ihrer einmaligen Besonderheit zu verstehen ist: Pessach als Erinnerungsfest an den Auszug aus Ägypten, das Wochenfest Schawuot, bei dem die Gesetzgebung auf dem Sinai zum Festthema wurde, später dann das Chanukka-Fest, bei dem man der Reinigung des von den Syrern entweihten Tempels durch Judas Makkabäus im Jahre 165 v. Chr. gedachte, der Nikanor-Tag, der an den Sieg des Judas Makkabäus über den syrischen Feldherren vier Jahre später erinnert oder das Purim-Fest, bei dem die persischen 
Juden die Errettung vor den Anschlägen des Haman durch Esther und Mordechai feierten. Vor allem in den letzten beiden vorchristlichen Jahrhunderten setzte sich der ereignisbezogene Gedenktagscharakter in der jüdischen Festkultur durch.

In der Entstehung und Entwicklung des christlichen Festkalenders wurden viele Elemente dieser historisch orientierten jüdischen Festkultur übernommen und weiterentwickelt. Ihr heilgeschichtlicher Bezugspunkt war nun das Erlösungsgeschehen. Entscheidend für

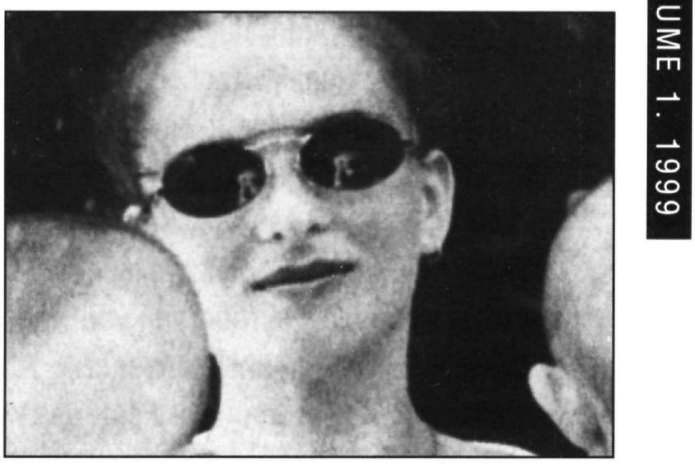
den spezifischen "Memorialcharakter" des Christentums erscheint jedoch ein neues Moment: Das älteste und wichtigste Basissymbol der neuen Glaubensgemeinschaft ist ein Gedächtnismahl. Es wurde in Erinnerung an das Letzte Abendmahl, das Jesus nach dem Bericht der Evangelien mit dem ausdrücklichen Auftrag, es zu seinem Gedenken zu wiederholen, an sein Leiden, sein Sterben und seine Auferstehung feierlich begangen. Die ältesten Bezeichnungen für dieses Gedächtnismahl sind "Herrenmahl" und "Eucharistiẹ". In der katholischen Tradition hat sich später die Bezeichnung "Messe" durchgesetzt. Ein Grundelement dieser zentralen Kultfeier ist "Anamnesis", "Memoria", Erinnerung. Für die spezifische Form des Erinnerns von Geschichte bei Festen in christlichen Kulturen hat die Messe eine enorme Bedeutung erlangt. Sie bildet ein Grundmuster, das nicht nur in religiösen, sondern vor allem auch in säkularisierten Formen von Gedenkfesten bis in die Gegenwart weiterwirkt.

Am Anfang des christlichen Erinnerns an Festtagen steht das wöchentliche Gedenken,, nicht das jährliche - schon gar nicht das Feiern von Geschichte über größere zeitliche Distanzen, wie es dem modernen Jubiläum zugrundeliegt. Die Gemeinde trifft sich am ersten Tag der Woche, am Sonntag, am "Tag des Herrn", an dem sie seine Auferstehung feiert. Der Sonntag ist der christliche Fest- und Gedenktag schlechthin. An inm wird grundsätzlich das Gedächtnismahl gefeiert. Das Gedächtnis der Auferstehung bestimmt dann auch die Anfänge des jährlichen Gedenkens im Christentum. Das älteste im Jahreszyklus begangene Fest ist Ostern. Andere Erinnerungsfeste an das Erlösungsgeschehen schließen hier an. Auf das Leben Jesu bezogene, jährlich gefeierte Feste bilden die Grundstruktur des christlichen Festkalenders.

Mit den Anfängen der Heiligenfeste, die schon ins 2. Jahrhundert zurückreichen, kommt ein neues Element hinzu: Nicht nur das Leben Jesu allein ist nun heilsgeschichtlicher Bezugspunkt der christlichen Gedenkkultur. Auch die Todestage der Märtyrer und später der Bekenner werden im Jahresrhythmus gefeiert. Dasselbe gilt für die Kirchweihfeste der großen Hauptkirchen in Jerusalem und Rom, die seit dem vierten Jahrhundert hinzukommen, die Kreuzfeste wie Kreuzauffindung und Kreuzerhöhung und schließlich jährliche Erinnerungsfeste an Konzilien, wie sie in Byzanz gefeiert werden. Der Rahmen der Gedenkanlässe weitet sich. Er bleibt aber auf Heilgeschichte in einem umfassenderen Verständnis beschränkt.

Der Weg vom heilgeschichtlichen zum politischen Gedenkfest war lange. Entscheidende Schritte auf diesem Weg wurden in Byzanz vollzogen. Den Heiligenfesten kam dabei eine 
entscheidende Vermiittlerfunktion zu. Besonders früh, nämlich bereits im 7. Jahrhundert, feierte man hier schon Herrschersiege mit jährlichen Dankfesten an Heilige. Eine besondere Rolle spielte dabei die Vorstellung, daß der militärische Erfolg oder auch andere politisch wichtige Ereignisse dem jeweiligen Tagesheiligen zu verdanken seien, der an seinem Festtag über besondere Kraft verfüge. So konnte sich in der Einkleidung christlicher Heiligenverehrung eine politische Gedenktagskultur ausbilden. Im Westen wurde dieses Muster zuerst von Venedig übernommen. Die Eroberung von Konstantinopel durch den Dogen Enrico Dandolo 1204 beging man jährlich am Nikolausfest. Die Anniversarien von drei Siegen über die Genuesen im 14. Jahrhundert wurden am Fest des heiligen Martial, Maria Magdalenas und zu Johannis Enthauptung begangen. Es entwickelte sich so auf der Grundlage des kirchlichen Heiligenkalenders eine Staatsliturgie, in der das politisch-historische Gedenken immer stärker in den Vordergrund trat. Venedig wurde diesbezüglich für andere italienische Kommunen zum Vorbild. Aber auch in der Schweiz und in Deutschland finden sich bereits im Spätmittelalter Schlachtengedenktage an Heiligenfesten als eine weit verbreitete Erscheinung, vor allem in Städten. Gelegentlich trat schon damals das Heiligengedenken völlig zurück. Damit zeichnet sich eine Form des Feierns von Geschichte ab, wie sie in den öffentlichen Gedenktagen der Moderne, den National- und Staatsfeiertagen, inren uns vertrauten Ausdruck findet.

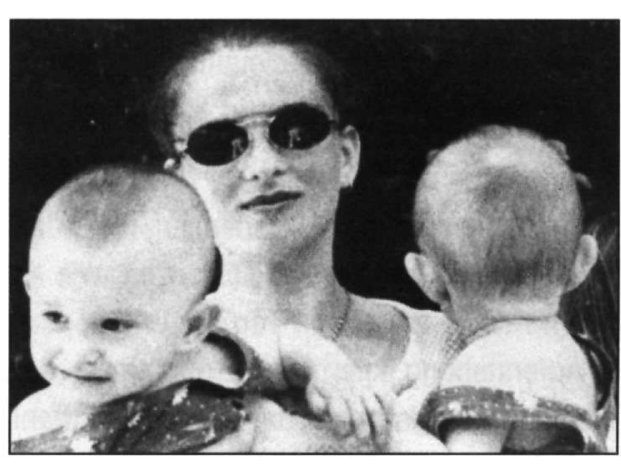

Zum Unterschied vom Anniversarium, dem jährlich wiederkehrenden Gedenktag, war das Jubiläum als historisches Erinnerungsfest über eine grössere zeitliche Distanz dem Mittelalter fremd. Das verdient besonders betont zu werden, weil unser Begriff Jubiläum aus dem Mittelalter stammt und mit einem Zeitrhythmus verbunden ist, der bis heute die Abstände von Jubiläumsfeiern bestimmt. Am 22. Februar des Jahres 1300 erließ Papst Bonifaz VIII. eine Bulle, in der er rückwirkend ab Weihnachten das Jahr als "annus iubilaeus" verkündete. In diesem Jubeljahr sollte in Rom ein vollkommener Ablaß gewonnen werden können. Mit der Bezeichnung "annus iubilaeus" knüpfte der Papst seinerseits an das biblische Vorbild des Jubeljahres an. Im Buch Levitikus heißt es "Du sollst sieben Jahreswochen, siebenmal sieben Jahre zählen; die Zeit von sieben Jahreswochen ergibt für dich neunundvierzig Jahre. Im siebten Monat, am zehnten Tag des Monats sollst du das Signalhorn ertönen lassen; am Versöhnungstag sollt ihr das Horn im ganzen Land ertönen lassen. Erklärt dieses fünfzigste Jahr für heilig und ruft Freiheit für alle Bewohner des Landes aus! Es gelte euch als Jubeljahr." Das Widderhorn, mit dem am Versöhnungstag jedes fünfzigsten Jahres die heilige Zeit angekündigt wurde, hieß "jobel”. Die Bezeichnung "annus iubilaeus" bzw. Jubiläum ist von diesem Widderhorn abgeleitet. Und auch das Zeitintervall von fünfzig Jahren lebt in den Jubiläumsabständen moderner Gedenktage fort. Mit dem Feiern von Geschichte hat aber weder das Jobel-Jahr des alten Israel noch das päpstliche Jubeljahr des Spätmittelalters zu tun, das sich auf jenes beruft. 
Das jüdische Jobel-Jahr war eine sakralrechtlich-sozialpolitische Einrichtung. Alle fünfzig Jahre sollten in Schuldknechtschaft geratene Israeliten freigegeben, verlorener Landbesitz zurückerstattet, Schulden nachgelassen werden. Es ging also um Wiederherstellung der gesellschaftlichen Ordnung zu bestimmten heiligen Zeiten. Das päpstliche Jubeljahr hingegen gehört in den Bereich der Heilsökonomie. Der vollkommene Ablaß, der in diesem Jahr allen Rompilgern unter bestimmten Gebetsauflagen gewährt wurde, sollte den Nachlaß aller Sündenstrafen bewirken. Es ging also um Bußzeiten - nach der Durchsetzung des Fegefeuerglaubens in der Westkirche ein ganz existenzielles persönliches Problem. Wenn sich Papst Bonifaz VIII. bei der Einrichtung des römischen Jubeljahrs auf das alttestamentarische Vorbild berief, so war das der Versuch, etwas wesentlich Neues aus der Berufung auf die Heilige Schrift zu legitimieren. Wie diese so folgenreiche Neueinrichtung des "annus iubilaeus" zu erklären ist, bleibt eine letztlich nicht voll geklärte Forschungsfrage. Es gibt wichtige Vorstufen in "Heiligen Jahren", die von Bischöfen proklamiert wurden, etwa in Canterbury, in Bamberg, vielleicht auch in Santiago di Compostela. Durch eine Initiative von oben allein kann jedoch die Entstehung des römischen Jubeljahrs nicht erklärt werden. Bonifaz VIII. reagierte nämlich mit seiner Bulle auf eine religiöse Volksbewegung. Für die römische Kurie unerwartet hatten sich am 1. Jänner 1300 zahllose Pilger in der Peterskirche eingefunden, die sich einen vollkommenen Ablaß erhofften. In dieser Bewegung von unten wird man vielleicht millenaristische Strömungen vermuten dürfen. Die Hoffnung auf ein Tausendjähriges Reich des Friedens und der Freude, das Christus am Ende dieser Weltzeit nach der Ankündigung der Geheimen Offenbarung errichten würde, war gerade in Italien im Spätmittelalter ein sehr wirkkräftiges Motiv der Volksfrömmigkeit. So ist nicht auszuschließen, daß bei der Entstehung der römischen Jubeljahre auch Millenarismus im Spiel war. Aber auch diese mögliche Kontinuitätslinie hat nichts mit historischem Gedenken zu tun.

Jubeljahre, Gnadenjahre, Heilige Jahre wurden von den Päpsten in unterschiedlichen Zeitabständen einberufen. Hundert, fünfzig, dreiunddreißig, schließlich fünfundzwanzig Jahre galten als das richtige Intervall, wofür sich jeweils eine geeignete biblische oder pastorale Erklärung fand. Die Bürger von Rom drängten meist auf eine häufigere Abhaltung, war doch der Pilgerstrom in die Heilige Stadt für sie eine ertragsreiche Einnahmequelle. Die Vorbereitungen der Heiligen Jahre haben vielfach das Stadtbild von Rom maßgeblich verändert. Zum Unterschied von modernen Jubiläen handelt es sich ja beim römischen Jubeljahr um eine heilige Zeit, die an heilige Orte gebunden ist. Trotz mancher Akzentverschiebungen hat es bis ins 20 . Jahrhundert hinein seinen Grundcharakter als Ablaßjahr bewahrt. Es geht nicht um Erinnerung an historische Ereignisse. Und es geht auch nicht um religiöses Feiern von markanten Einschnitten in unserem Zeitrechnungssystem. Mag sein, daß im Heiligen Jahr 2000 solche Momente mit hereingenommen werden. Seiner Tradition nach ist das römische Jubeljahr trotz seiner Bezeichnung "annus iubilaeus" ein Relikt aus einer Zeit, in der es noch keine Jubiläen gab.

Wesentliche Wurzeln für das Entstehen von Jubiläen in unserem heutigen Verständnis liegen im Reformationszeitalter. Vom jährlich gefeierten Reformationsfest über das nach jeweils hundert bzw. fünfzig Jahren gefeierte Reformationsjubiläum führt eine direkte Entwicklungslinie zu den nationalstaatlichen Jubiläen der Moderne. Dem Jubiläum geht das Anniversarium voraus. Schon 
früh wurde in jährlichen Feiern des Reformators bzw. der Reformation gedacht. Bezeichnend erscheint, daß bei der Tageswahl die personenbezogenen Daten von Luthers Geburts-, Taufbzw. Sterbetag immer mehr in den Hintergrund treten. Letztlich setzt sich die Bezugnahme auf ein Ereignis als heilsgeschichtlich bedeutsamer Neuanfang durch - nämlich auf den Theseanschlag von Wittenberg am 31. Oktober 1517. Nicht personen- sondern ereignisbezogen wurden auch die ersten Reformationsjubiläen begangen - 1580 in Erinnerung an die Augsburger Konfession, 1617 erstmals an den Thesenanschlag.

Wie kam es zu dieser Entwicklung von jährlichem Gedenken zum Gedenken über größere zeitliche Distanz? Bezeichnungen und Intervalle scheinen auf das römische Jubeljahr zu verweisen. In Hinblick auf die religionspolitische Situation ist jedoch eine unmittelbare Beeinflussung auszuschließen. Eine gemeiısame Grundlage war für Protestanten und Katholiken im jüdischen Jobel-Jahr gegeben. Auf dieses konnte man sich als biblische Legitimation berufen, das neue Phänomen des Geschichte-Feierns in größeren Zeitabständen aber läßt sich aus dieser Wurzel nicht befriedigend erklären. Zwei Faktoren dürften für die Entwicklung besonders bedeutsam gewesen sein: einerseits das neue Geschichtsbewußtsein des Protestantismus, andererseits das neue Jahrhundertdenken der Zeit. Beide sind miteinander in Zusammenhang zu sehen. Dieser Zusarımenhang läßt sich anschaulich an einem richtungsweisenden Frühwerk der protestantischen Geschichtsschreibung veranschaulichen, den sogenannten "Magdeburger Zenturien", die von Matthias Flacius Illyricus und seinen Mitarbeitern ab 1559 veröffentlicht wurden.

Die großen historiographischen Werke des Mittelalters begannen - ihrer heilsgeschichtlichen Konzeption entsprechend - mit der Erschaffung der Welt. Flacius' Kirchengeschichte verläßt erstmals diesen Rahmen. Er beginnt mit der Geburt Christi. Christus als Ausgangspunkt der Darstellung entsprach der Grundintention des Geschichtswerks. Es ging ja nicht allgemein um Weltgeschichte als Heilgeschichte, sondern um die Entfaltung eines besonderen Gedankens: Es sollte gezeigt werden, daß die lutherische Lehre die von Jesus verkündete sei, die dann im Lauf der Jahrhunderte immer mehr verfälscht wurde. Mit der Geburt Christi als Beginn der Darstellung ergab sich eine Koinzidenz mit dem Beginn der christlichen Zeitrechnung. Zum ersten Mal in der Historiographiegeschichte kamen geltende Ära und dargestellter Geschichtsabschnitt voll zur Deckung. Und noch ein Zweites war in den "Magdeburger Zenturien” neu, nämlich die Einteilung in "Hundertscharen" von Jahren, die dem Werk seinen eigentümlichen Namen gab. Für die Autoren hatte die Jahrhundertgliederung rein praktische Bedeutung, um die Fälle des gebotenen Stoffs zu ordnen. Daß diese Zeiteinheit gewählt wurde, ist sicher kein Zufall. Das 16. Jahrhundert ist ja eine Epoche, in der sich eine starke Tendenz einerseits zur abstrakten Zeitrechnung, andererseits zum Dezimalsystem erkennen läßt. Das Denken in Jahrhunderten war den Zeitgenossen keineswegs so selbstverständlich, wie man es aufgrund ihrer Zeitrechnung vermuten würde. Darauf verweist besonders deutlich der Sachverhalt, daß das deutsche Wort "Jahrhundert" erst im 17. Jahrhundert aufgekommen ist. Das englische "century" dürfte direkt durch den Einfluß der "Magdeburger" Zenturien entstanden sein. Bis dahin fehlt eine Bezeichnung. Aus der Kombination von Einteilung nach Jahrhunderten und Beginn mit der christlichen Zeitrechnung entstand mit diesem Basiswerk protestantischer 
Geschichtsschreibung ein zukunftsweisendes Ordnungsmodell: die von Christi Geburt an zählende Jahrhundertrechnung.

Die enorme Breitenwirkung der "Magdeburger Zenturien" hat nicht nur dazu geführt, daß sich die Jahrhundertrechnung als Ordnungsraster der Geschichte weithin durchsetzte, sie hat auch bewirkt, daß das Jahrhundert zunehmend als eine besonders bedeutsame Zeiteinheit angesehen wurde - und zwar in zweierlei Verständnis. War die Jahrhunderteinteilung bei Flacius Illyricus noch ein rein formales Einteilungsprinzip, wurde in der Folgezeit zunehmend mehr darin gesehen. Man sprach von einem "genius saeculi". Man übertrug alte Vorstellungen vom Wesen der Weltalter auf das Jahrhundert - daß mit dem ausklingenden Jahrhundert etwas Altes zu Ende gehe, daß mit dem neuen etwas Neues beginne. Die Jahrhundertschwellen wurden in diesem Sinne als besonders bedeutungsvoll angesehen und dementsprechend gefeiert. Solche Feiern fanden erstmals 1700 statt und erfuhren dann 1800 und 1900 eine noch viel größere Beachtung. Worum es dabei eigentlich ging, wird aus einer regelmäßig aus diesem Anlaß wiederkehrenden und heftig diskutierten Streitfrage deutlich: Beginnt das neue Jahrhundert am 1. Jänner 1700, 1800, 1900? Oder ist der Jahresanfang des Folgejahrs - also 1701, 1801, 1901 der entscheidende Anfangstermin? Ein Jahr Null hatte ja Dionysius Exiguus im 6. Jahrhundert noch nicht gekannt, als er mit seiner Berechnung von Christi Geburt die Grundlage unserer Zeitrechnung schuf. Daß sich bei den Feiern eindeutig die Wende von 99 zu 100 durchsetzte, zeigt deutlich die Bedeutsamkeit, die hier der "runden Zahl" beigemessen wurde - eine säkularisierte Zahlenmystik ohne religiöse Grundlage. Es wurde ja auch die Silvesternacht zur gefeierten Wende, nicht das Geburtsfest Christi, mit dem das Heilige Jahr beginnt. Die Jahreswende von 1999 zu 2000 wird die erste Jahrtausendschwellenfeier im Sinne dieses historisch relativ jungen Typs von Jubeljahren sein. Zu Anfang des Jahres 1000 hat man einen solchen übergang ganz sicher nicht gefeiert. Ein Bewußtsein besonderer Bedeutsamkeit von Jahrhunderten und Jahrhundertwenden war der damaligen Zeit fremd. Soweit die Menschen damals von millenaristischen Ängsten erfültt waren, hat sich dieses Bewußtsein, in einer besonderen Zeit zu leben, auch nicht in Jubelstimmung ausgedrückt.

Das neue Denken in Jahrhunderten, das in der frühen Neuzeit aufgekommen ist, hat sich zunächst im Feiern von Jubiläen ausgewirkt - früher jedenfalls als im Feiern von Jahrhundertwenden. Zur ersten Jahrhundertfeier der Reformation im Jahre 1617 deutete einer der Autoren einer Schrift zum "Lutherischen Jubelfest" den Anlaß des Feierns: "inmittelst ein ganzes Seculum verflossen und eben dieses 1617. Jahr gleichsam natalitius unserer reformirten Evangelischen Religion ist". Nach Ablauf eines Saeculums wird "gleichsam ein Geburtstag" gefeiert. Die übliche Frist für die Feier des Geburtstags war das Jahr. Jahr und Jahrhundert werden in dieser Stelle parallelisiert, und damit Anniversarium und Jubiläum. Das "Saeculum" gilt hier im neuen Verständnis der Zeit als ein sich geschlossener Zeitabschnit. Erst damals entstand ein Zeitbewußtsein, das dem Jahrhundert diesen Stellenwert beimaß bzw. ein Geschichtsbewußtsein, daß das Jahrhundert im Geschichtsablauf so hoch bewertete. So ist es kein Zufall, daß sich erst damals analog zum Anniversarium ein Typus von Jubeljahren ausbildete, der das Gedenken an Geschichte zum zentralen Thema der Jubelfeier machte. Die Unterschiede zum Anniversarium sind nicht grundsätzlicher Natur. Sie liegen in der Intensität 
des Feierns und in der größeren zeitlichen Distanz, die sicher mit der Steigerung in der Intensität zu tun hat. Die Intervalle der Distanz verweisen - über das neue Jahrhundertdenken hinaus - auf Jubeljahre älterer Zeit mit anderem Charakter, mit denen sie vor allem die Zahlenmystik in der Beistimmung solcher "heiliger Zeiten" gemeinsam haben. Neue Komponenten kommen in die traditionellen Formen christlicher Memorialkultur durch den veränderten Zugang zur Geschichte - zunächst eine aus dem Geist der Reformation neu gedeutete Heil- bzw. Kirchengeschichte, zunehmend aber dann auch ein säkulares Geschichtsbewußtsein, das in Staat und Nation seine wichtigsten aktuellen Bezugspunkte hat.

Den jährlich gefeierten Reformationstagen sowie den in größeren zeitlichen Abständen begangenen Reformationsjubiläen kommt für die Entstehung und damit für das Verständnis der modernen Gedenktagskultur entscheidende Bedeutung zu. Das gilt für deren Rahmenbedingungen, für deren Inhalt, deren Gestaltungsformen. Während in der katholischen Kirche das ursprünglich bischöfliche Recht, über kirchliche Festfeiern zu entscheiden, mit zunehmender Zentralisierung auf den Papst überging, übernahm es in den evangelischen Landeskirchen der Landesfürst - ein entscheidender Schritt zur Säkularisierung und Politisierung der Gedenkkultur. So wie die Initiative zu den Reformationsfeiern von den Landesfürsten

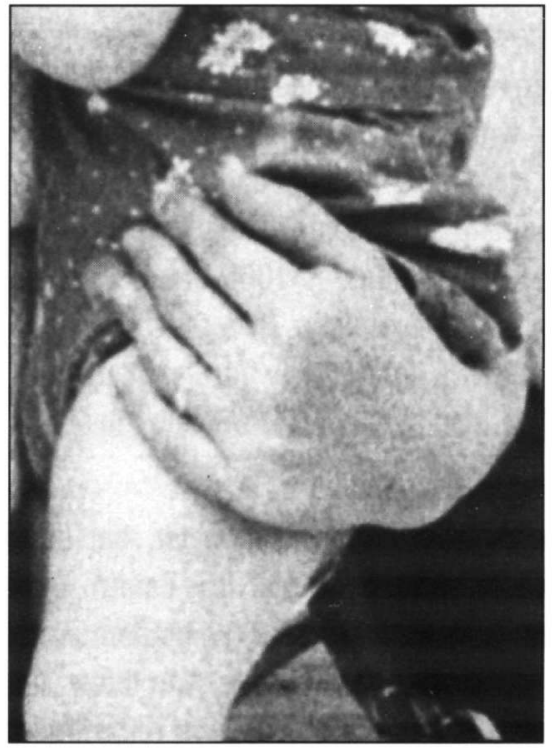
ausging, so zunehmend auch zur Gestaltung anderer historischer Gedenkfeste. Neben dem durch die Reformation beeinflußten Geschichtsbewußtsein sind es also auch strukturelle Bedingungen der Kirchenverfassung, die zu einem Vorsprung der protestantischen Länder in der Ausbildung einer säkularen Jubiläen- und Gedenktagskultur gegenüber den katholischen Ländern geführt haben. Zu den Anlässen solcher Gedenkfeste sind die Grenzen zwischen religiös bedeutsamen und politisch wichtigen vielfach fließend. Symptomatisch dafür ist etwa das Wartburgfest von 1817, bei dem 300 Jahre Reformation zugleich mit dem vierten Jahrestag der Völkerschlacht bei Leipzig gefeiert wurde. Es ging also in doppelter Weise um einen "heiligen Anfang" - den der erneuerten Religion und den der von Fremdherrschaft befreiten Nation. Aus heilsgeschichtlich christlichen Wurzeln kommend setzt sich dieses Feiern des "heiligen Anfangs" gleichsam wie ein Leitmotiv in den Gedenktagen und Jubiläen des nationalistischen Zeitalters fort. Nur die Ereignisse, auf die man sich bezieht, sind andere: siegreiche Schlachten, die die nationale Freiheit begründeten, die Erklärung der Unabhängigkeit, die Proklamation der Verfassung. Ebenso stehen die historischen Gedenkfeste für Freiheitshelden und nationale Heroen in der heilsgeschichtlichen Tradition des Kults als heilbringend bzw. als heilig verehrter Personen. Dieser Kontinuitätszusammenhang beantwortet uns die Frage: Warum feiern wir Geschichte? Jubiläen und historische Gedenktage haben ihren Ursprung im religiösen Fest. 
Spezifische Gestaltungsformen des religiösen Feierns leben in ihnen auch noch in säkularisierter Form weiter.

Das Kernstück christlicher Liturgie, die Feier der Eucharistie, blieb bis ins 19. und 20. Jahrhundert hinein auch zentrales Element aller öffentlichen Gedenkveranstaltungen. Daß kein Reformationsfest und kein Reformationsjubiläum ohne Festgottesdienst stattfinden konnte, versteht sich von selbst. Dasselbe galt für historische Gedenktage der katholischen Kirche. Aber auch die dynastisch-höfische und sie ablösend die staatlich-nationale Festtagskultur behielt die Messe als Mittelpunkt des Festablaufs bei. Selbst in der Französischen Revolution wurde noch der erste Jahrestag des Sturms auf die Bastille mit einer großartigen Festmesse begangen. Die wesentliche Position, die der Messe in der Gestaltung öffentlicher Gedenktage zukam, bedeutet allerdings nicht, daß das historische Gedenken hier dominant durch die spezifische Form des Erinnerns, wie sie für die Messe typisch ist, geprägt wurde. Die Messe war ja nur ein Teil der Gedenktagsveranstaltungen. Der Bezug zum jeweiligen historischen Anlaß erfolgte mehrheitlich in anderen Gestaltungselementen der Festtagsliturgie. Viele von ihnen gehen aber wiederum auf einzelne gottesdienstliche Formen der Messe zurück, sind quasi ausgelagerte Elemente der Messe. Die Messe ist ihrem Wesen nach Vergegenwärtigungsliturgie des Heilgeschehens. In mehr oder minder vermittelter Weise wirkt dieser Grundzug christlicher Memorialkultur in den unterschiedlichsten Formen des Feierns von Geschichte an öffentlichen Gedenktagen nach - oft weit von der ursprünglichen Wurzel entfernt.

Ein zentrales Element aller historischen Gedenkfeiern war die Festansprache. Wurde sie im Rahmen des Festgottesdiensts gehalten, so als Predigt. Außerhalb desselben stand sie unverkennbar in dieser Tradition - in den rhetorischen Gestaltungsformen, im feierlichen Pathos, in den vermittelten Inhalten. Vor allem die protestantische Predigtkultur bot für die Entwicklung der Festansprache besonders günstige Voraussetzungen. Die Predigt ist jenes Gottesdienstelement, das sich am flexibelsten gestalten läßt. Deswegen eignet es sich auch in besonderer Weise dazu, historische Bezüge aufzunehmen. Die Interpretation der Heiligen Schrift in der Predigt bedeutete ja ihrem Wesen nach, Bezüge zwischen einst und jetzt herzustellen. Genau das aber war auch die Aufgabe des Festredners. Das gesprochene Wort erlaubte bei diesem Umgang mit Vergangenheit sehr unterschiedliche Zugangsweisen - von statischem Festhalten an geheiligter Tradition bis hin zu aktualisierender Neudeutung. Wo die Festrede dem Predigtmodell verhaftet blieb, tendierte sie dazu, Geschichte als sakrale Tradition zu betrachten.

Festspiel und Theater als Gestaltungselement historischer Gedenktage in neuerer Zeit führen ebenfalls zu christlich-liturgischem Ursprung zurück, freilich in ganz anderer Zugangsweise zur Geschichte als die Predigt als verbale Verkündigungsform. Festspiel ist in seiner Wurzel illustrierende Predigt durch lebende Bilder, durch Zurschaustellen von Gruppenszenen. An solche "repraesentationes sacrae" schließen Oster-, Passions- und Heiligenspiele an. Sie führen aus der Kirche hinaus zum Festspiel, zum Theater. Auch Festumzüge mit szenischen Bildern aus der Geschichte zu historischen Gedenktagen gehen auf diese Wurzel zurück. Bei solchen szenischen Bildern aus der Geschichte, bei Festspiel, bei Theater handelt es sich um eine besonders anschauliche Form der Vergegenwärtigungsliturgie. Sie spricht noch stärker die 
Emotion an als das in der Predigt gesprochene Wort. Sie drückt in noch eindringlicherer Weise aus, daß Vergangenheit und Gegenwart in eins gesehen werden sollen.

Zusammenhänge zwischen der Gestaltung historischer Gedenktage und traditionellen christlichen Liturgieformen sind in vielfältiger Weise feststellbar. Vor allem das Lied ist diesbezüglich zu nennen. Das liturgische Element der Hymne wurde im 19. Jahrhundert zur Nationalhymne weiterentwickelt, häufig mit historischen Bezügen im Text. Kaum eine andere Form bringt die Weihestimmung des Feierns von Geschichte so stark zum Ausdruck wie das Singen von Hymnen. Das Läuten der Glocken als Mittel, festliche Stimmung zu bewirken, ist ebenfalls ein Moment aus religiöser Tradition. Eine wichtige Kontinuitätslinie zwischen christlichen und säkularen Gestaltungsformen der Festliturgie stellt der aus der Prozession herausentwickelte Festzug dar. Im 19. Jahrhundert haben historische Festzüge zu Gedenktagsanlässen eine besondere Blüte erlebt. Alle diese Formen waren geeignet, eine sakrale Feierstimmung zu bewirken. Mit der Säkularisierung und Nationalisierung des historischen Gedenkens wurde solches Instrumentarium der Stimmungsbildung auf neue Inhalte bezogen.

Aus den Kontinuitätslinien zwischen den Traditionen christlicher Liturgie und den Gestaltungsformen von Jubiläen und Gedenktagen in neuerer Zeit lassen sich einige Grundzüge des spezifischen Verhältnisses zur Geschichte ableiten, das bei solchen Anlässen zum Tragen kommt. Das wichtigste Moment ist wohl, daß es an solchen Tagen um das Feiern von Geschichte geht. Das Feiern von heilgeschichtlich bedeutsamem Geschehen ist - wie gezeigt wurde ein genuin christliches Prinzip. Die "memoria" spielt in der christlichen Liturgie eine zentrale Rolle. Die säkularen Liturgien von Jubiläen und öffentlichen Gedenktagen schließen an solche Traditionen an. Feiern von Geschichte ist eine ganz besondere Form des Umgangs mit Vergangenheit. Die Weihestimmung der Gedächtnishandlung spricht das Gefühlsleben der Teilnehmer an, nicht das Denken. Es geht um emotionale Bindung, nicht um kritische Distanz. Das bei Jubiläen gepflegte Geschichtsbewußtsein entfernte sich mit der Entwicklung der Geschichte zur Wissenschaft immer mehr von jenen Formen, wie sie für wissenschaftliche Beschäftigung mit Vergangenheit charakteristisch sind. 'Nur wenige Elemente der traditionellen Festliturgie waren geeignet, eine Verbindung zu wissenschaftlich betriebener Geschichte herzustellen - die aus der gedruckten Festpredigt herausentwickelte Festschrift etwa oder die Ausstellung, die die früher so häufig aus Jubelanlässen errichteten Denkmäler ersetzte. Aber selbst bei solchen Elementen der neueren Gedenkkultur ist die Wissenschaftlichkeit stets gefährdet. Die Festschrift muß Vergangenheit so darstellen, daß sie den Jubel in der Gegenwart nicht gefährdet. Die Ausstellung darf nur das zeigen, was zu einem positiven Geschichtsbild paßt.

Im Feiern von Geschichte übernahmen Jubiläen viele Traditionen christlicher Vergegenwärtigungsliturgie. Tendenziell bedeutet das die Negation des Unterschieds von Vergangenheit und Gegenwart, ein mystisches Erleben des Einswerdens mit der Geschichte. Das Gedenken des "heiligen Anfangs" bietet immer Anlaß, die "Einheit mit dem Ursprung" zu beschwören. "So wie damals so auch heute" gehört zu den Leitmotiven von Jubiläumsansprachen. Das bei öffentlichen Gedenktagen gepflegte Geschichtsbewußtsein ist 


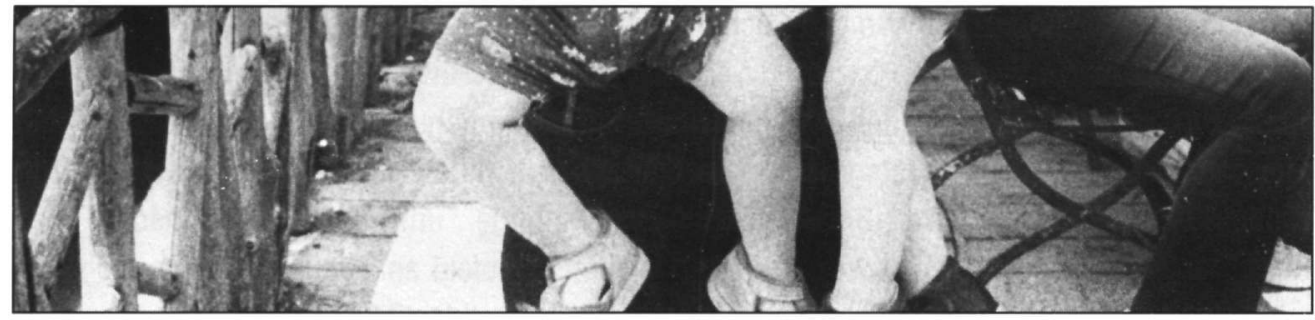

grundsätzlich statisch. Formulierungen wie "Europa- Erbe und Auftrag der Christen" zum Türkenjahr oder "500 Jahre Evangelisierung Lateinamerikas" mit der Aufforderung zur "Neuevangelisierung" zum Columbus-Jubiläum sind für diese Einstellung typisch. Es wird etwas aus der Vergangenheit gleichbleibend übernommenes gedacht, das es in die Zukunft weiter zu tradieren gilt. Solche "Jubiläumsaufträge" sind meist ahistorische Konstrukte. Das ist aber wohl die harmlosere Seite. Vielfach wird dabei Geschichte als Legitimationsideologie für politische Ziele in der Gegenwart benützt. Diese ideologische Komponente ist sicher die gefährlichere.

Den religiösen Wurzeln von Jubiläen entsprechend geht es bei dieser Form des Feierns von Geschichte vielfach auch um Glauben an Geschichte. An der überlieferung der Heilsgeschichte darf nicht gerüttelt werden, weil sie als Geschichte Heil vermittelt. Aber auch die säkulare Heilgeschichte des nationalistischen Zeitalters stellte ihre Ursprungsmythen nicht in Frage. Über das Tradierte hinaus führte sie oft noch zu zusätzlicher Mythenbildung. Fand sich in der Vergangenheit nicht das, was in der Gegenwart repräsentiert werden sollte, so ließ sich die Geschichte auch umschreiben. Für Jubiläen gilt grundsätzlich: Das jeweilige Bild von der Vergangenheit wird von der Situation in der Gegenwart bestimmt. Die Tendenz zur Mythen- und Legendenbildung begleitet die Geschichte des Jubiläen-Feierns. Aufgrund von Gegenwartsinteressen verzerrte, ja mitunter sogar handfest verfälschte Geschichtsbilder sind das Resultat dieses spezifischen Umgangs mit Vergangenheit. Vieles etwa, was im Zusammenhang mit dem Columbus-Jubiläum von 1992 gesagt und geschrieben wurde, läßt sich ohne übertreibung als Verfälschung und Verzerrung qualifizieren. Korrekturen durch die Wissenschaft sind seitens der Veranstalter von Jubiläen meistens nicht gefragt. Und bei den Veranstaltern liegt die Macht, ihr Geschichtsbild durchzusetzen. Innen entgegenzutreten, kann dann zur Aufgabe wissenschaftlicher Redlichkeit werden. In demokratischen Gemeinwesen besteht die Möglichkeit dazu - allerdings auch hier mit geringen Chancen auf Erfolg. Wo Geschichte gefeiert wird, hat jedenfalls das Geschichte-Glauben vor dem GeschichteDenken Vorrang.

Aus seinen religiösen Wurzeln hat das Feiern von Geschichte bei Jubiläen und Gedenktagen seine wichtigste Funktion übernommen: die Integration gesellschaftlicher Gruppen durch Identitätsbildung aus der Geschichte. Christliches Feiern hatte diese Funktion durch viele Jahrhunderte geleistet, sowohl auf Iokaler wie auf universaler Ebene. Moderne Staatlichkeit und nationale Einheitsbewegungen schlossen an dieses Instrumentarium der Identitätsbildung an, um überregionale Gemeinschaftsbildung zu schaffen. Sie taten es mit denselben Mitteln wie die christlichen Religionsgemeinschaften, inhaltlich aber vielfach in Konkurrenz mit ihnen. Nationale Geschichte trat oft als Ersatzreligion auf. Sie wurde zum Symbol der angestrebten bzw. der 
realisierten nationalen Einheit. Wo Geschichte Identifikationssymbol wird, ist für eine analytische Geschichtswissenschaft kein Platz. Mit seiner Gegenüberstellung von "kritischer Forschung" und "offiziöser Geschichte der Gedenktage", jener "Forschung gegen die landläufigen Vorstellungen" und "dem Staatsgedächtnis, das der Staat durch die Geschichtswissenschaft kontrolliert" spricht Pierre Bourdieu dieses wichtige und von der Theorie der Geschichtswissenschaft viel zu wenig beachtete Spannungsfeld an. Die Konkurrenz, die einer kritisch-analytischen Geschichtswissenschaft durch eine identifikatorische Zugangsweise gemacht wird, ist aber vielleicht noch die geringere Gefahr. Ein gewisses Maß an Identitätsstiftung durch Geschichte braucht ein Gemeinwesen wohl auch heute noch. Beim Feiern von Geschichte zu Jubiläumsanlässen geht allerdings das richtige Maß nicht selten verloren. Die Grenzen zwischen historisch begründetem Patriotismus, Nationalismus und Chauvinismus sind fließend. Im Kontext der politischen Situation Frankreichs im Jahr 1996 setzte Le Pens Formulierung von Chlodwigs Taufe als Gründerakt der ältesten Nation Europas und einer der größten Zivilisationen der Welt sicher nicht nur einen falschen, sondern auch einen gefährlichen Akzent. Das Papstwort von "Frankreich, älteste Tochter der Kirche" spricht ähnliche Stimmungslagen an. Viel bedenklicher ist die eurozentrische Überheblichkeit, wie man sie vielfach in Ansprachen aus Anlaß des Jubiläums der Entdeckung Amerikas 1992 hören konnte. Bei all den eingangs angesprochenen Papstbesuchen aus Jubiläumsanlässen - vom Türkenjahr 1983 angefangen - war im Vorfeld stets davon die Rede, daß Triumphalismus vermieden werden solle. Solche frommen Vorsätze sind sicher positiv. Es wird aber dabei verkannt, daß Triumphalismus in unseren überkommenen Formen des Feierns von Geschichte bei Jubiläen tief verankert ist. Er läßt sich bei dieser Feiertradition nur schwer vermeiden.

Mit der Integrationsfunktion von Geschichte-Feiern nach innen korrespondiert die Abgrenzung nach außen. Die Jubiläen des 19. und 20. Jahrhunderts haben durch ihren spezifischen Umgang mit Geschichte viel zur Produktion von Feindbildern beigetragen. Die nationale Abgrenzung durch Geschichte hatte in der konfessionellen ihre Vorläufer. Bei Reformationsjubiläen etwa wurde in manchen Territorien den Predigern aufgetragen, die Identität von Papsttum und Antichrist "zu beweisen". Auf katholischer Seite blieb man diesbezüglich nichts schuldig. Zu den religiös fundierten Feindbildern gehörte auch die mit dem Sieg auf dem Kahlenberg von 1683 so eng verbundene Vorstellung vom "Erbfeind der Christenheit" - bis in die jüngste Vergangenheit hinein Anlaß um Kreuzzugs-Verpflichtungen zu beschwören. Die Jubiläen im Gedenken an 1683 dienten aber nicht nur immer wieder dazu, das Türken- bzw. Islam-Feindbild zu pflegen. Anschaulich läßt sich an der Geschichte dieser Jubeljahre auch die Austauschbarkeit von Feindbildern zeigen. 1783 wurde aus diesem Anlaß zum Kampf gegen die Aufklärer aufgerufen, 1883 gegen die Liberalen, 1933 gegen die Bolschewiken - als neue Gefahr aus dem Osten besonders gut in das Schema passend. 1983 dürften die Warnungen im Vorfeld bereits angekündigte Formen einersolchen ideologischen Aktualisierung noch rechtzeitig abgefangen haben. Gerade Schlachtenjubiläen haben die Tendenz, einen Feind ins Spiel zu bringen, gegen Aen man heute kämpfen muß. Das Denkmuster "So wie damals so auch heute" verleitet dabei uft zu kühnen Parallelen. Aber nicht nur das Gedenken an Siege hat derart gefährliche Wirkungen. Mit dem identifikatorischen Geschichtsbild, das beim Feiern von Jubiläen in 
besonderer Weise zum Tragen kommt, ist durch die Aufwertung der eigenen Gruppe implizit auch eine Abwertung des Fremden gegeben. Die euro- und christianozentrischen Feiern des Columbus-Jahrs waren von den jeweiligen Veranstaltern nicht als bewußte Abwertung der IndioKulturen geplant. De facto aber haben sie diesen Effekt gehabt - in der Tradition der überkommenen Jubiläumskultur eine notwendige Konsequenz.

Nicht alle Jubiläen haben die weltpolitische Brisanz des Gedenkjahrs an die sogenannte "Entdeckung Amerikas" Jubiläen werden ja auch im Kleinen gefeiert - von Gemeinden, Vereinen, Firmen etc. Was hier aus heils- und nationalgeschichtlichen Traditionen des Geschichte-Feierns an Gefahren abgeleitet wurde - hat das alles wirklich auch im Mikro-Maßstab seine Geltung? Sicher - Kantönli-Geist ist eine geringere Gefahr als nationaler Chauvinismus. Und der Philatelistenverein wird bei seinem Jubelfest keine besonderen Feindbilder aufbauen. Anders ist es vielleicht zu bewerten, wenn die Festrede beim Stiftungsfest einer Studentenverbindung den Geist der Gründer beschwört und damit gegen die Aufnahme von Studentinnen heute argumentiert. Auch die Firmenfestschrift, die die Rolle der Belegschaft ausblendet oder die Verstrickung in der NS-Zeit übergeht, ist nicht ganz so harmlos. Die Geschichte des GeschichteFeierns gibt ein Instrumentarium in die Hand, das im Großen wie im Kleinen die Risken aufzeigt, die mit dieser spezifischen Umgangsweise mit Vergangenheit verbunden sind.

Auch in eine andere Richtung wird eine Geschichte des Geschichte-Feierns weiterzudenken sein: Die Gedenktagskultur ist nicht bei den im 19. Jahrhundert erreichten Formen stehen geblieben. Es gibt, wie schon erwähnt, Elemente des Feierns von Jubiläen, die eher mit wissenschaftlich betriebener Geschichte vereinbar sind - etwa Festschriften oder Ausstellungen. Und solche neuere Formen haben gegenüber den traditionellen - jedenfalls in Österreich - in den letzten Jahrzehnten deutlich an Bedeutung gewonnen. Jubiläen sind damit harmloser geworden, allerdings auch langweiliger. Denn die Jubelstimmung der traditionellen Festliturgie war es doch, die Jubiläen ihre Attraktivität verlieh. Auch die jubiläumskritischen Diskussionen der letzten Jahre mögen dazu beigetragen haben, daß mit Inszenierungen des historischen Gedenkens heute vielfach vorsichtiger umgegangen wird. Daraus einen generellen Trend zu weniger gefährlichen Jubiläen ableiten zu wollen, wäre sicher vorschnell. Man braucht sich nur vor Augen führen, in welcher Form und mit welchen fatalen Folgen das Jubiläum der Schlacht auf dem Amselfeld 1989 vom Milosevic-Regime manipuliert wurde. Die Gefahren des Geschichte-Feierns sind weltweit sehr unterschiedlich. Die österreichische Situation läßt sich sicher nicht verallgemeinern.

Auch dann, wenn Jubiläumsgeschichte frei ist von den Gefahren der Selbstüberschätzung, der Abwertung des Fremden, des Beharrens in überholtem Traditionalismus, auch dann ist sie als Zugangsweise zur Vergangenheit nicht unproblematisch. Auch wenn Jubiläen nicht schaden, so nützen sie wenig. Viel an fachlichen Ressourcen ist gebunden, weil man sich immer wieder dem "Zwang der runden Zahl" verpflichtet fählt. Gerade in Zeiten, in denen die Mittel für die Wissenschaft knapper werden, ist die Frage erlaubt, welchen gesellschaftlich wesentlichen Ertrag denn die Jubiläumsgeschichte erbringt. Bourdieu hat schon recht, wenn er die Aufgaben einer modernen Geschichtswissenschaft als Gegenpol zu einer "offiziösen Geschichte der 
Gedenktage" sieht, "die sich der Verwaltung des kollektiven Gedächtnisses widmet”. In einer Zeit, in der sich unsere alläglichen Lebenswelten, unsere elementaren menschlichen Grundbefindlichkeiten mit einer Radikalität und einem Tempo wandeln, wie noch nie zuvor in der Weltgeschichte, hat Geschichtswissenschaft wohl wichtigere Aufgaben als Jubiläumsfeiern vorzubereiten.

Was es mit diesem vermeintlichen "Zwang der runden Zahl" auf sich hat, der das Jubiläenkarussell immer von neuem antreibt, das zeigt uns die Geschichte des GeschichteFeierns deutlich. Der angebliche Zwang aus der Vergangenheit ist in Wirklichkeit ein Interesse der Gegenwart, insbesondere das Interesse derer, die die Macht haben zu bestimmen, was denn wie zu welchem Zweck gefeiert werden soll. Jubiläen und Gedenktage werden begangen, wenn sie in ein vorgegebenes politisches Konzept passen. Um dieses Kriterium zu erfüllen, muß notfalls auch die Zahl nicht so ganz "rund" sein. 950 Jahre ist sicher kein klassisches Jubiläums-Intervall. Hat man sich einmal auf ein wichtiges Datum des Feierns festgelegt, kann der "Zwang der Tradition" hinzukommen. Aber auch dieser "Zwang" bedeutet sicher keine verpflichtende Bindung. Daß man dem Jubiläum 950 Jahre Österreich fünfzig Jahre später ein Millennium folgen ließ, war primär eine politische Entscheidung.

Die Wurzel jener runden Zahlen, die heute so vielen zwingend erscheinen, wird aus der Geschichte des Geschichte-Feierns klar. Heilige Zahlen liegen zugrunde, die im alten Testament begründet sind, heilige Zeiten, die nach dem Ablauf einer heiligen Zahl von Jahren wiederkehrend gedacht werden - das Sabbatjahr, und als seine Potenzierung das Jobel-Jahr. Dem Mittelalter war solche Zahlenmystik wichtig. Und als sich in der frühen Neuzeit das Dezimalsystem durchsetzte, kamen neue Bedeutsamkeiten solcher Zahlen für "heilige Zeiten" hinzu. Aber was haben wir heute mit solcher Zahlenmystik zu tun? Was verpflichtet uns zur Feier? Was veranlaßt uns zu Jubel?

Irrationale Zahlenmystik liegt auch jenem anderen Typus von Jubeljahren zugrunde, den wir traditionell begehen: der Jahrhundertschwellenfeier. Die Geschichte des Feierns dieser Anlässe läßt ebenso Zusammenhänge erkennen, die ein besseres Verstehen ermöglichen. Mit dem Aufkommen des Jahrhundertbewußtseins in der frühen Neuzeit ist der letztlich in heilsgeschichtlichen Konzeptionen verankerte Gedanke einer besonderen Bedeutsamkeit von Epochen auf das Jahrhundert der Zeitrechnung übergegangen. Die Vorstellung eines besonderen "genius saeculi" kommt auf. Man glaubt, daß mit der Jahrhundertwende etwas Altes zu Ende geht, etwas Neues anfängt. Solche Vorstellungen sind schlichtweg Begriffsgespenster. Die Annahme läßt sich durch nichts erhärten, daß sich gerade in Jahrhundertjahren etwas Wesentliches verändert hätte. Das Jahr 2000 wird zu irrationaler Zahlenmystik noch in zusätzlicher Weise Anlaß geben. Aus heilsgeschichtlichem Denken stammende Endzeiterwartung können sich mit dem Millennium verbinden. Als vermeintliches Schwellendatum trennt es nicht nur "Altes" und "Neues" von Jahrhunderten sondern sogar von Jahrtausenden. Aber was geht hier eigentlich an "Altem" zu Ende? Was wird am "Neuen" neu sein? Das Denken in Jahrhundert- und Jahrtausendschwellen imaginiert historische Zäsuren, wo sie gar nicht gegeben sind. Und wer macht im "neuen Jahrhundert", im "neuen Jahrtausend" 
denn alles neu? In heilsgeschichtlichen Konzeptionen ließ sich diese Frage noch leicht beantworten. In einem säkularisierten Geschichtsdenken ist die Vorstellung eines sich gleichsam von selbst vollziehenden übergangs von Alt zu Neu nicht nur irrational sondern auch gefährlich, weil sie zur Passivität verleitet. In einer sich rasant verändernden Gesellschaft wird mehr denn je aktives Handeln zur Notwendigkeit. Was es in dieser Welt zu verändern gibt und wie solche Veränderung möglich wäre, das müssen wir aus einem anderen Umgang mit Geschichte lernen als dem Beschwören von Begriffsgespenstern.

Vortrag gehalten an österreichischen Nationalfeiertag, am 26. Oktober 1996 im Wiener Rathaus.

Auswahlbibliographie des Autors zu der hier behandelten Thematik:

Das Babenbergerjubiläum - ein Beitrag zum Selbstverständnis unserer Gesellschaft heute? in: Jubiläen und Geschichtsbowußtsein, Beiträge zur historischen Sozialkunde 6, 1976, S. 49-52

Perché le celebrazioni giubilari? in: Quaderni Storici 47, 1981, S. 177-181

Politischer Katholizismus, Österreichbewußtsein und Türkenfeindbild. Zur Aktualisierung von Geschichte bei Jubiläen in: Türkenjubiläum 1983. Heroenkult oder Strukturanalyse, Beiträge zur historischen Sozialkunde 12,

1982, S. $111-120$

"Eine merkwürdige, schöne Verbundenheit ...". Das Türkenjubiläum im österreichischen Fernsehen, in: Geschichte-Fernsehen, Sept. 1983, S. 24ff.

Jubilei in zgodowinska zavest, in: Oto Luthar (Hg.) Sodobne teorije zgodovinopisja, Ljubljana 1990, S. 174-196 Jubilees, monuments and history, in: Sveti mesta na Balkanite, Blagoevgrad 1996, S. 245-255

Anniversarium und Jubiläum. Zur Entstehung und Entwicklung öffentlicher Gedenktage, in: Emil Brix und Hannes Stekl (Hgg.), Der Kampf um das Gedächtnis. Öffentliche Gedenktage in Mitteleuropa, Wien 1997, S. 23-90.

\section{S u m mary}

\section{Jubilees and Other Anniversaries: Why do we celebrate history?}

Anniversaries do not only concern the past. They also concern the present. It is however difficult to relate the celebration of history with other forms of study of the past. Nobody really objects to the celebration of historical events. But do we really need a history of celebrations? If we agree that there have to be celebrations of the past, then we are obliged to undertake the responsility to reflect seriously on the ways in which the history of celebrating influences political and social consciousness. A great part of this responsibility lies with historians. The history of anniversaries is different from critical historical disciplines in terms of its aims and methods. The former however must constitute an object of study for the latter.

Seen in a progressive way the origins of historical anniversaries are traced in religion. The celebration of history in particular "sacred times" does not constitute a widespread religious practice. The celebration of history is however related to the particular importance of memory within a religion; it is also related to the ways in which 
religious practices establish a special culture of celebrating.

In Christianity the memory of different events of salvation has acquired a particular importance. The emphasis on events of salvation is shared by Christianity and Judaism. There is a great difference between religious celebrations and political anniversaries. The celebration of victories in war on the same dates as the celebration of saints in the Byzantine period constituted a link between these two different forms of celebration. In the West, similar forms of celebration were adopted in Venice.

The origins of historical anniversaries in their contemporary form can be traced to the period of Reformation. The celebration of historical events was grounded on the new historical consciousness of Protestantism and the new fascination with the concept of the millenium in that period. The fact that religious celebrations and other anniversaries were dependent on the decision of local hegemons contributed to the gradual secularization and politicization the culture of celebrating history.

Public celebrations cultivate static forms of historical consciousness. History, however, is used in many different ways in order to legitimize political ideologies in the present. During the 19th and 20th centuries, historical celebrations were used in order to produce negative images of national enemies. From this perspective the popularity of historical celebrations forces us to consider their possible impact on society. The concepts of the century and the millenium are founded on the notion of clear points of change in history. In the context of secular thought the notion of canonical transition from the 'old' to the 'new' is not only illogical, it is also dangerous since it encourages passivity. In our period of transition it is necessary to think about change through an approach to history that would differentiate itself from practices of exorcism of conceptual ghosts.

This article was based on a speech that was deliverd on the 26th of October 1996 at the City Hall of Vienna on the occasion of the the Austrian National Day. It will be soon published in the Wiener Vorlesungen series.
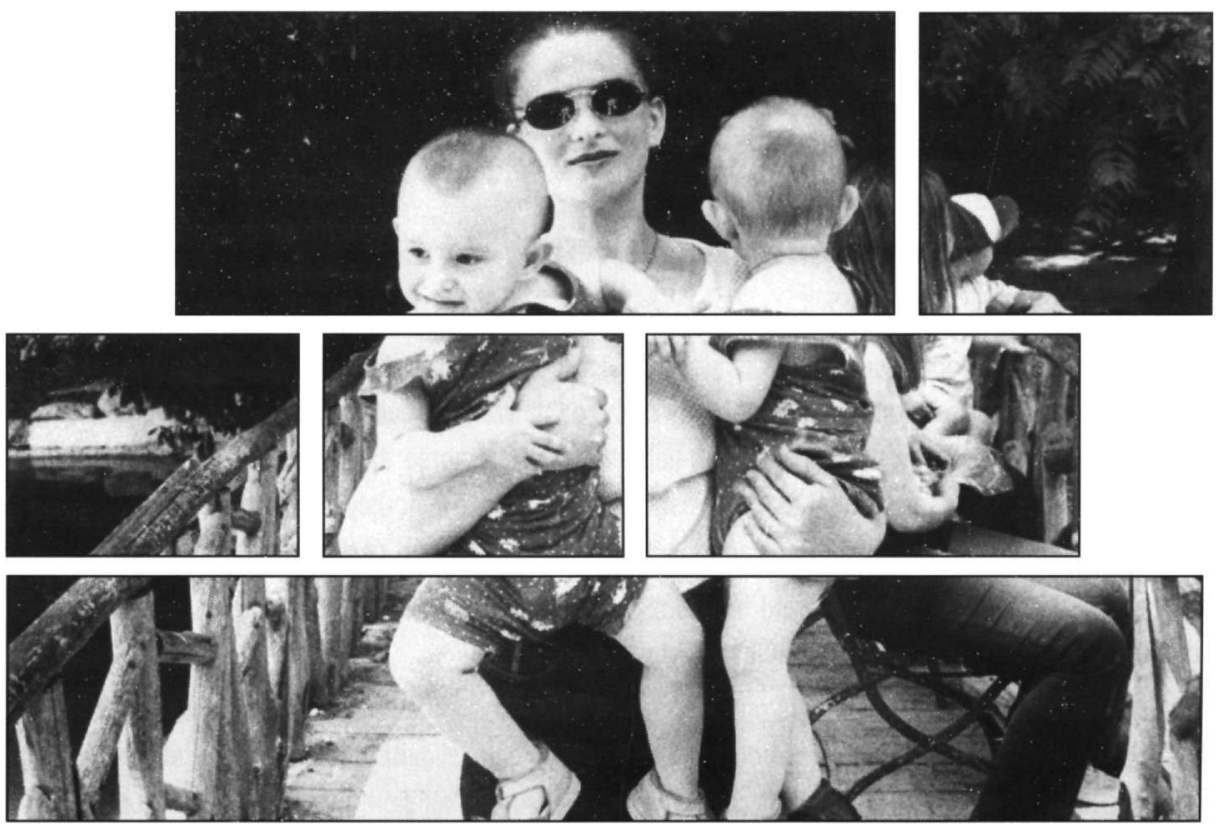